\title{
Influence of Building Air Tightness on Energy Consumption of Ventilation System in Nearly Zero Energy Residential Buildings
}

\author{
Wei Liu ${ }^{1}$, Zhen $\mathrm{Yu}^{2, *}$, Jianlin $\mathrm{Wu}^{2}$, Huai $\mathrm{Li}^{2}$, Caifeng $\mathrm{Gao}^{2}$, and Hongwei Gong ${ }^{1}$, \\ ${ }^{1}$ College of Urban Construction, Nanjing Tech University, Nanjing 210009, Jiangsu, China \\ ${ }^{2}$ China Academy of Building Research, Beijing 100020, China
}

\begin{abstract}
Building air tightness increased quickly in recent years as nearly zero energy buildings concept gradually drawn more attentions from the industry. Ventilation system plays an important role for the indoor air quality control in residential buildings with good air tightness. The energy consumption of the ventilation system is a significant part of the overall energy consumption of low energy residential building. The influence of the building air tightness on the energy consumption of ventilation system was not addressed sufficiently in previous studies. This paper analyses the quantitative relations between building air tightness, energy recovery efficiency and ventilation system control strategy. A mathematical model of the heating and cooling energy consumption in residential buildings is proposed, which takes building air tightness, energy recovery efficiency and control strategy of ventilation system as major input parameters. Equivalent COP of ventilation energy recovery system is proposed as an energy efficiency index of the ventilation system. It can be used as a criterion to decide the optimal design parameters of nearly zero residential buildings in different climate conditions.
\end{abstract}

\section{Introduction}

Building air tightness is an important performance indicator of the nearly zero energy buildings. Different climate zones should have different building airtightness requirements. This is especially true for the countries like China who has a vast territory and complex climate conditions. In the "Technical Guidelines for Passive Low Energy Residential Buildings" published by Chinese government in 2015 [1], a reference value from the European standard was adopted. It was required that the low energy residential buildings should has airtightness of 0.6 air changes per hour at 50 Pascals pressure (hereinafter referred to as $\mathrm{N}_{50}$ ). With good building air tightness, the energy loss caused by the air infiltration can be greatly reduced. On the other hand, the mechanical ventilating system becomes necessary in such buildings of good airtightness, which consumes additional energy. An optimal trade-off exists between the energy saving from the heat recovery of exhausted air and the additional energy consumption of the mechanical ventilation system. In different climatic conditions, the quantitative relationships between the energy consumption of ventilation, building air tightness, and heat recovery efficiency are different.

Many studies addressed the of the impact of building air tightness on building energy consumptions. The ISO 13790-2008 standard [2] gives the effect of air infiltration on the energy consumption of building ventilation systems. Jokisalo [3] studies that the relationship between airtightness value under test condition and normal operational condition. Persil [4] conducted long-term test which shows that $33 \%$ of the cooling and heating load is caused by the air infiltration. The experiment results indicates that the volum of building infiltration under 50 $\mathrm{Pa}$ is about 20 times of that under normal pressure. In China's "Standard for on-site testing of energy efficient civil buildings engineering" DB11/T555, the relational value is 17 times.

Simonson [5] studied Finnish residential buildings and found that for heat recovery efficiency of $70 \%, 50 \%$, and $0 \%$, the energy consumption would increase by 2.7 $\mathrm{kWh} /\left(\mathrm{m}^{2} / \mathrm{a}\right), 4.5 \mathrm{kWh} /\left(\mathrm{m}^{2} / \mathrm{a}\right)$ and $9.2 \mathrm{kWh} /\left(\mathrm{m}^{2} / \mathrm{a}\right)$ for each $0.1 \mathrm{~h}^{-1}$ increase of air exchange rate. At an air exchange rate of $0.5 \mathrm{~h}^{-1}$, for every $10 \%$ increase in energy recovery efficiency, energy consumption of $3.3 \mathrm{kWh} /\left(\mathrm{m}^{2} / \mathrm{a}\right)$ can be reduced. Zhang X.D [6] used building energy simulation tool to calculate the annual load of buildings under different airtightness levels of doors and windows in Nanjing City. When the airtightness is increased from level 1 to level 8 , the cumulative load in the heating season is reduced by $51.5 \%$, while the cumulative load in the air conditioning season was reduced by $32.6 \%$, and the cumulative load reduction for the whole year reached $46.7 \%$. Peng C. [7] studied the impact of air tightness on heating energy consumption and found that as the air tightness increased in the hot summer and cold winter climate zone of China, the energy consumption of the fans increased significantly, which causes the total energy consumption of heating increased despite the heat recovery efficiency increase. Most relevant researches use simulation tools to study typical buildings to evaluate the

\footnotetext{
*Corresponding author: yuzhen@.chinaibee.com
} 
importance of air tightness. Detailed analysis of the influence mechanism between the air tightness and building energy consumption, especially the energy consumption of fresh air, is insufficient. The applicability of the research results is constrained by the selection of typical buildings.

LV Y.J. [9] studied the influence of frost protection and preheating in winter energy recovery devices on energy consumption of nearly zero energy buildings in cold climate zones. A calculation method was proposed to calculate the thermal load and annual cumulative ventilation heating load. Adopting $\mathrm{Lv}$ 's calculation method, $\mathrm{Xu} \mathrm{W}$. [10] proposed a correction method to estimate the deviations of fresh air heating load and energy consumption caused by different operating schedule in office and residential buildings. The energy consumption of fresh air heating in residential buildings can be reduced by $24 \%$ to $31 \%$ when operational schedule is optimized. For office buildings, the reduction rate can reach $65 \%$. For every $5{ }^{\circ} \mathrm{C}$ of increase of preheating set temperature, the recovered heat reduced by $7 \%$ to $10 \%$. The above researches only focus on the heating mode of cold climate zones. Further research on other climate zones and cooling mode has not been well addressed.

This paper studies the quantitative relationship between air tightness and energy consumption of ventilation systems in nearly zero energy residential buildings. Considering the usage mode and operating time of ventilation system, the effects of different building air tightness and annual energy consumption of ventilation system in different climate zones, different control strategies and different energy recovery efficiency are analyzed. Equivalent COP of ventilation energy recovery system is proposed as an energy efficiency index of the ventilation system. It can be used as a criterion to decide the optimal design parameters of nearly zero residential buildings in different climate conditions.

\section{Ventilation system energy consumption calculation method}

\subsection{Ventilation volume of buildings}

In China, GB 50736-2012 " Design code for heating, ventilation and air conditioning in civil buildings" [11] stipulates that the minimum amount of ventilation required for residential buildings should be determined according to the method of air change rate. The number of air changes in residential buildings should be in accordance with the values given in Table 1 .

Table 1. The number of minimum fresh air changes $N s$ in residential buildings

\begin{tabular}{|c|c|}
\hline living area per capita $F_{P}$ & air changes per hour \\
\hline$F_{P} \leqslant 10 \mathrm{~m}^{2}$ & 0.70 \\
\hline $10 \mathrm{~m}^{2}<F_{P} \leqslant 20 \mathrm{~m}^{2}$ & 0.60 \\
\hline $20 \mathrm{~m}^{2}<F_{P} \leqslant 50 \mathrm{~m}^{2}$ & 0.50 \\
\hline$F_{P}>50 \mathrm{~m}^{2}$ & 0.45 \\
\hline
\end{tabular}

Building design ventilation volume $V$ :

$$
V=A \times h \times N_{S}
$$

Where: $A$ is the usable area inside the building, $\mathrm{m}^{2} ; h$ is the height of the building space used, $\mathrm{m}$; $N s$ is the number of air changes, $\mathrm{h}^{-1}$.

The heating and cooling load caused by the air infiltration driven by wind pressure and hot pressure should be taken into the overall building heating and cooling load[12]. According to ISO 13790 [2], the relationship between the air change rate of test condition and normal operation condition is:

$$
\begin{gathered}
V_{N}=0.3 \times 1.3 \times V_{B} \\
N_{V, \text { Rest }}=\frac{V_{N 50} \cdot N_{50} \cdot e}{V_{N}} \\
V_{\text {in }}=A \times h \times N_{V, \text { Rest }}
\end{gathered}
$$

Where: $V_{N}$ is the ventilation volume under normal operation, $\mathrm{m}^{3} / \mathrm{h} ; 0.3$ is the minimum number of air changes in the building, $\mathrm{h}^{-1} ; 1.3$ is the ventilation correction coefficient; $V_{B}$ is the usable space volume, $\mathrm{m}^{3}$; $N_{V, \text { Rest }}$ is the number of air infiltration changes under normal pressure, $\mathrm{h}^{-1} ; \mathrm{V}_{\mathrm{N} 50}$ is the air infiltration under the pressure of $50 \mathrm{~Pa}, \mathrm{~m}^{3} / \mathrm{h}$; $e$ is the building wind resistance coefficient; $V_{\text {in }}$ is the air infiltration under normal pressure, $\mathrm{m}^{3} / \mathrm{h}$.

ISO standard 13790-2008 gives the corresponding wind resistance coefficient $e$ according to the degree of exposure of the building and the degree of occlusion. The value of the wind resistance coefficient is $0.01 \sim 0.1$.

The ventilation volume of residential building design consists of two parts: air infiltration volume and mechanical ventilation volume. When the fresh air volume requirement is given, if the building has better air tightness, the air infiltration will be smaller, and the corresponding mechanical ventilation volume should be larger to maintain indoor air quality.

$$
\begin{gathered}
N_{s}=N_{V}+N_{V, \text { Rest }} \\
V_{V}=A \times h \times N_{V}
\end{gathered}
$$

Where: $N_{S}$ is the number of ventilation takes from table 1; $N_{V}$ is the number of mechanical ventilating rate, $\mathrm{h}^{-1} ; V_{V}$ is the mechanical ventilation rate, $\mathrm{m}^{3} / \mathrm{h}$.

\subsection{The calculation of the ventilation system's cooling and heating load}

It is assumed that the ventilation system does not bear the indoor load and only processes to the indoor setting state. The heating load $q_{l}$ of the ventilation system consists of the preheating load $q_{p}$, the auxiliary heating load $q_{h}$ (heating load required for mechanical ventilation after energy recovery treatment) and the air infiltration heating load $q_{\text {in }}$; cooling season ventilation system load $q_{2}$ consists of auxiliary cooling load $q_{c}$ and air infiltration cooling load $q_{\text {in } 2}$.

Heating load:

Cooling load:

$$
q_{1}=q_{p}+q_{h}+q_{\text {in } 1}
$$

$$
q_{2}=q_{c}+q_{\text {in } 2}
$$

When the temperature is lower than the minimum operating temperature of the energy recovery device, the frost may grow on the heat recovery unit. The outdoor fresh air needs to be preheated before entering the heat recovery unit, and the preheating set-point temperature is 
$t_{\text {set. }}$. When the outdoor dry bulb temperature is $t_{o}<t_{\text {set }}$, the preheating load of the ventilation system is:

$$
q_{P}=c_{P} \rho_{\text {air }} V_{V}\left(t_{\text {set }}-t_{o}\right) / 3600
$$

Where: $q_{p}$ is the preheating load, $\mathrm{kW} ; c_{p}$ is the specific heat of air, $\mathrm{kJ} /(\mathrm{kg} \cdot \mathrm{K}) ; \rho_{\text {air }}$ is the air density, $\mathrm{kg} / \mathrm{m}^{3} ; t_{\text {set }}$ is the preheating set-point temperature, ${ }^{\circ} \mathrm{C} ; t_{o}$ is outdoor dry bulb temperature, ${ }^{\circ} \mathrm{C}$.

Calculating the auxiliary heating load of the ventilation system in the heating season should consider two situations: when the outdoor temperature $t_{o}$ is less than the preheating load set temperature $t_{\text {set }}$, preheating is required, and the auxiliary heating load is calculated using equation (10). If the outdoor temperature $t_{o}$ is higher than the set temperature $t_{\text {set }}$ of the preheating load, the auxiliary heating load is calculated using the equation (11).

$$
\begin{gathered}
q_{h}=c_{P} \rho_{\text {air }} V_{V}\left(t_{\text {room }}-t_{\text {set }}\right)\left(1-\eta_{t}\right) / 3600 \\
\quad\left(t_{o}<t_{\text {set }}\right) \\
q_{h}=c_{P} \rho_{\text {air }} V_{V}\left(t_{\text {room }}-t_{o}\right)\left(1-\eta_{t}\right) / 3600 \\
\left(t_{o}>t_{\text {set }}\right)
\end{gathered}
$$

Where: $q_{h}$ is the auxiliary heating load of the ventilation system, $\mathrm{kW} ; t_{\text {room }}$ is the indoor design temperature, ${ }^{\circ} \mathrm{C} ; \eta_{t}$ is the sensible heat exchange efficiency of the total energy recovery unit.

Auxiliary ventilation cooling load in cooling season:

$$
q_{c}=\rho_{\text {air }} V_{V}\left(h_{o}-h_{\text {room }}\right)\left(1-\eta_{h}\right) / 3600
$$

Where: $q_{c}$ is the auxiliary cooling load of the ventilation system, $\mathrm{kW} ; h_{o}$ is the outdoor air enthalpy, $\mathrm{kJ} / \mathrm{kg}$. $h_{\text {room }}$ is the indoor setting enthalpy, $\mathrm{kJ} / \mathrm{kg} ; \eta_{h}$ is enthalpy efficiency of heat recovery unit.

Heating load from infiltration:

$$
q_{\text {in } 1}=c_{P} \rho_{\text {air }} V_{\text {in }}\left(t_{\text {room }}-t_{o}\right) / 3600
$$

Cooling load from infiltration:

$$
q_{\text {in } 2}=\rho_{\text {air }} V_{\text {in }}\left(h_{o}-h_{\text {room }}\right) / 3600
$$

\subsection{Calculation of annual cumulative heating and cooling load caused by ventilation and infiltration}

The calculation of the heating load and cooling load caused by ventilation and infiltration is critical for the analysis of energy consumption in nearly zero energy buildings. This paper uses the temperature hours and enthalpy hours method. Given the meteorological data and indoor set values, the heating and cooling loads in equations (7)-(14) are accumulated for 8760 hours. In the equations, $Q_{S 1}$ is the accumulated ventilation heat consumption; $Q_{S 2}$ is the accumulated cooling capacity; $Q_{P}$ is the accumulated preheating load; $Q_{h}$ is the accumulated auxiliary heating quantity, $Q_{c}$ is the accumulated auxiliary cooling consumption; $Q_{\text {in } 1}$ is the cumulative heating load caused by infiltration; and $Q_{i n 2}$ is the cumulative cooling load caused by infiltration, $\mathrm{kWh} / \mathrm{a}$.

\subsection{Control mode of the ventilation system}

In order to obtain the rational relationship between the air tightness of the building and the energy consumption of the ventilation system, the control strategy of the ventilation system should be considered properly. This paper calculates the quantitative relationship under the following three control modes.

\subsubsection{Set schedule mode (Mode 1)}

Time schedule can make big difference to the energy consumption of ventilation system. Taking the example of a typical working household, Table 2 gives the operating time table. The following simulation assumes that the ventilation system only runs within the set time.

Table 2 Operating of energy calculation for ventilation system

\begin{tabular}{|c|c|c|}
\multicolumn{4}{c}{ in residential buildings } \\
\hline $\begin{array}{c}\text { Status of } \\
\text { ventilation } \\
\text { system }\end{array}$ & $\begin{array}{c}\text { Work day } \\
\text { (Monday to } \\
\text { Friday) }\end{array}$ & $\begin{array}{c}\text { Weekend } \\
\text { (Saturday and } \\
\text { Sunday) }\end{array}$ \\
\hline on & $19: 00 \sim 8: 00$ & $000: 00 \sim 24: 00$ \\
\hline off & $08: 00 \sim 19: 00$ & 00 \\
\hline
\end{tabular}

\subsubsection{Manual control mode (Mode 2)}

In the cooling season, when the outdoor temperature is lower than a given value, occupants may tend to improve the indoor environment by opening the window using natural ventilation. Assume 22:00 as the time of occupants to go to sleep, the manual control mode assumes that before 22:00 the occupants will choose to use natural ventilation or mechanical ventilation according to the outdoor environment. In the winter, window opening cannot be used to increase the room temperature. The manual control strategy assumes that mechanical ventilation is the only ventilation mode in winter.

\subsubsection{Optimal automatic control mode (Mode 3)}

In the cooling season, a thermostat is used to choose between the natural ventilation mode or mechanical ventilation mode according to the outdoor environment. If the outdoor enthalpy is lower than the set value, natural ventilation will be chosen. If the outdoor enthalpy is higher than the set value, mechanical ventilation will be chosen. The decision change can be done at any time of the day without the limitation of sleeping time of occupants.

\subsection{Annual heating and cooling energy consumption caused by ventilation and infiltration}

Assume electric heating is used for the preheating in the winter to protect the heat recovery unit, and the heating efficiency is taken as $100 \%$ :

$$
E_{P}=Q_{P} \times 100 \%
$$

Where: $E_{P}$ is the preheating energy consumption, $\mathrm{kWh} / \mathrm{a}$. Assume the auxiliary cooling and heating energy consumption caused by ventilation and infiltration is done by heat pump:

$$
E_{H}=\frac{Q_{h}+Q_{i n 1}}{\varepsilon_{1}}
$$




$$
E_{C}=\frac{Q_{c}+Q_{i n 2}}{\varepsilon_{2}}
$$

Where: $E_{H}$ is the heat pump energy consumption for the auxiliary heating, $\mathrm{kWh} / \mathrm{a}, \varepsilon_{l}$ is the heating COP of heat pump; $E_{C}$ is the heat pump energy consumption for the auxiliary cooling, $\mathrm{kWh} / \mathrm{a}, \varepsilon_{2}$ is the cooling COP of the heat pump.

Energy consumption of the fan is:

$$
E_{F}=V_{V} \times P \times T
$$

Where: $E_{F}$ is the energy consumption of the ventilation fan, $\mathrm{kWh} / \mathrm{a} ; P$ is the power consumption of fan per unit air volume, $0.45 \mathrm{~W} /\left(\mathrm{m}^{3} / \mathrm{h}\right)[1] ; T$ is the operating time of the fan, $\mathrm{h}$

Equivalent $\mathrm{COP}$ of ventilation heat recovery system is proposed as an energy efficiency index, defined as follows:

$$
\begin{gathered}
C O P_{1}=\frac{Q_{1}}{E_{1}} \\
E_{1}=E_{P}+E_{H}+E_{F}
\end{gathered}
$$

Where: $\mathrm{COP}_{1}$ is the equivalent $\mathrm{COP}$ of ventilation heat recovery system in the heating season; $E_{1}$ is the total energy consumption of the ventilation system in the heating season, $\mathrm{kWh} / \mathrm{a} ; \mathrm{Q}_{1}$ is the total heating load of the fresh air, and the energy required to process the outdoor air to the indoor set parameters, $\mathrm{kWh} / \mathrm{a}$.

$$
\begin{gathered}
\mathrm{COP}_{2}=\frac{Q_{2}}{E_{2}} \\
E_{2}=E_{C}+E_{F}
\end{gathered}
$$

Where: $\mathrm{COP}_{2}$ is the equivalent $\mathrm{COP}$ of ventilation heat recovery system in the cooling season; $E_{2}$ is the total energy consumption of the ventilation system in the cooling season, $\mathrm{kWh} / \mathrm{a} ; \mathrm{Q}_{2}$ is the total cooling load of the fresh air, and the energy required to process the outdoor air to the indoor design parameters, $\mathrm{kWh} / \mathrm{a}$.

Equivalent COP of ventilation heat recovery system is proposed as an energy efficiency index. Without heat recovery system, all the heating and cooling load for fresh air supply will be taken by the heat pump. Therefore, if the equivalent COP is higher than the heat pump COP, the ventilation heat recovery system is more efficient than the traditional ventilation system without heat recovery, and vice versa.

\section{Calculation results and analysis}

This paper selects four typical cities in different climate zones of China (Harbin, Beijing, Nanjing, Guangzhou), and studies the effects of building air tightness on annual energy consumption of ventilation systemin using different different control strategies with different energy recovery efficiency.

From the equations (7) and (8), it can be seen that the energy consumption of ventilation system has nothing to do with the thermal parameters of building envelope, household type, window-wall ratio and other factors, and is directly proportional to the area of the building envelope. Therefore, this paper discusses the energy consumption of fresh air per unit area of the building envelope. Following values are chosen in the simulation: the indoor temperature is $20{ }^{\circ} \mathrm{C}$; the summer indoor temperature setpoint is $26{ }^{\circ} \mathrm{C}$; the relative humidity setpoint is $50 \%$; the enthalpy setpoint is $53 \mathrm{~kJ} / \mathrm{kg}$. The preheating start when the outdoor temperature is below $10^{\circ} \mathrm{C}$. The air source heat pump is used for both winter heating and summer cooling. In winter, the heat pump COP of Harbin is taken as 1.5 , the heat pump COP of
Beijing in winter is taken as 2.5 , and for the rest is taken as 3.5. The meteorological parameters are calculated as 8760 hours of meteorological parameters for different city built by the energy simulation software DeST. It used the generated meteorological parameters based on the measured data of 194 meteorological points provided by the China National Meteorological Center for 50 years [13].

\subsection{Energy consumption of ventilation system without natural ventilation (Mode 1)}

The ventilation system is used during the actual operating time in the building, without natural ventilation.

\subsubsection{Severe cold climate zone}

Figure 1 shows the energy consumption and equivalent COP ventilation system under different air tightness in Harbin (Severe Cold Climate). When the $\mathrm{N}_{50}$ is reduced from 1.3 to 0.3 , the energy consumption of the ventilation system in the heating season is reduced by 7.51 $\mathrm{kWh} /\left(\mathrm{m}^{2} \cdot \mathrm{a}\right)$, accounting for $26 \%$, and the equivalent COP of the ventilation energy recovery system is increased by 0.8 . Harbin is located in the severe cold area, where the outdoor minimum temperature can reach $-30^{\circ} \mathrm{C}$ in winter, and the outdoor temperature is lower than $-10^{\circ} \mathrm{C}$ for most of the time in winter. The heat recovery unit use a lot of energy to preheat the outdoor air. When $\mathrm{N}_{50}$ decreases from 1.3 to 0.3 , the energy consumption of ventilation system increases by $0.13 \mathrm{kWh} /\left(\mathrm{m}^{2} \cdot \mathrm{a}\right)$ in the cooling season, and the equivalent COP is also lower than that of the heat pump. It is mainly because that the temperature difference between indoor and outdoor in Harbin is small in summer. When the mechanical ventilation unit is turned on, the energy consumption of the fan is relatively large, whereas the energy recovery unit has relatively small benefit

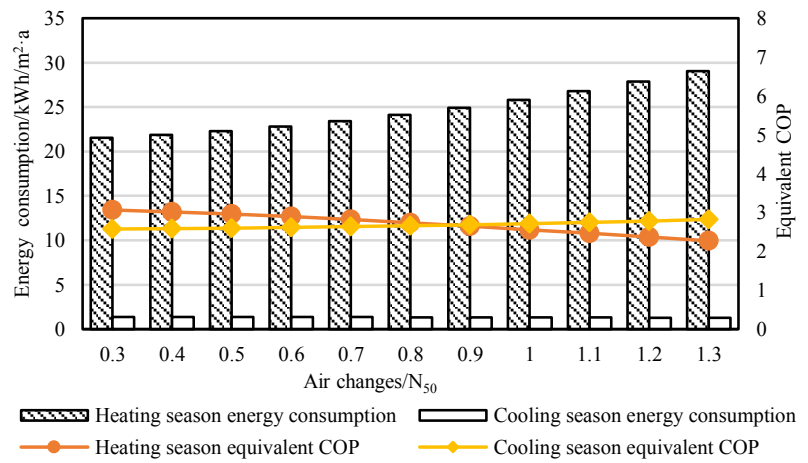

Fig.1. Energy consumption and equivalent $\mathrm{COP}$ of ventilation system under different air tightness in Harbin

\subsubsection{Cold climate zone and hot summer and cold winter climate zone}

Figure 2 and Figure 3 show the energy consumption and equivalent COP of the ventilation system in Beijing and Nanjing respectively. When the $\mathrm{N}_{50}$ decreased from 1.3 to 
0.3 , the energy consumption of the ventilation system in the heating season in Beijing and Nanjing is reduced by $32 \%$ and $23 \%$ respectively and the equivalent COP increased by 1.92 and 1.48 . When the $\mathrm{N}_{50}$ decreased from 1.3 to 0.3 , the energy consumption of the ventilation system in the cooling season in Beijing and Nanjing decreased by $7 \%$ and $20 \%$ respectively, and the equivalent $\mathrm{COP}$ of the ventilation energy recovery system increased by 0.3 and 1.2. Beijing's energy consumption in the cooling season has not decreased significantly with the decrease of $\mathrm{N}_{50}$, which is mainly because Beijing has a large amount of time during the operating hours in summer when the outdoor enthalpy is lower than the indoor set value. The heat recovered by the heat recovery unit is less than that of Nanjing while the fan is in in fulltime operation mode and consumes a lot of energy.

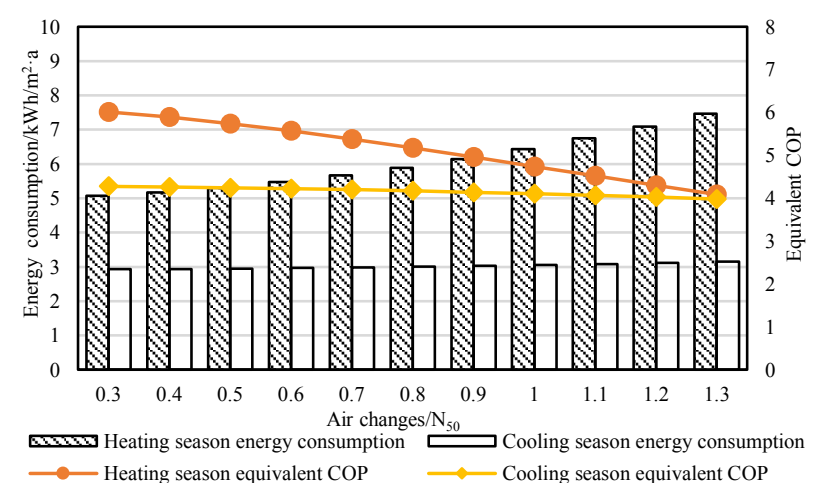

Fig.2. Energy consumption and equivalent COP of ventilation system under different air tightness in Beijing

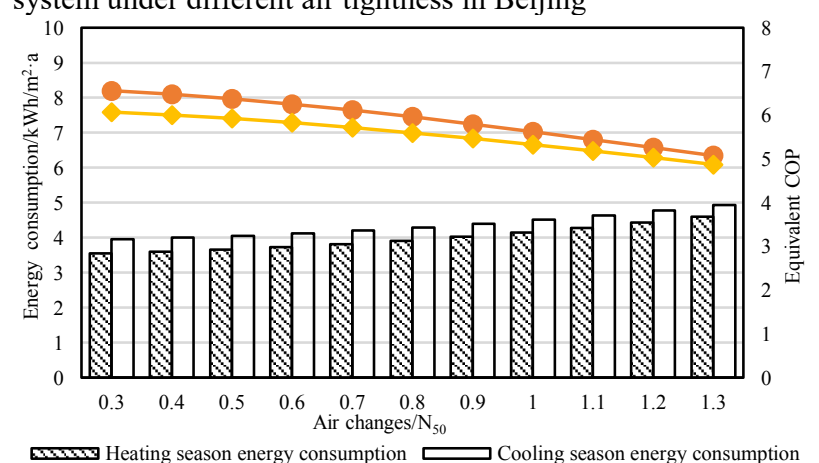

$\longrightarrow$ Ceating season energy consumption
Cooling season energy consump
- Heating season equivalent COP

Fig.3. Energy consumption and equivalent COP of ventilation system under different air tightness in Nanjing

\subsubsection{Hot Summer and Warm Winter Climate Zone}

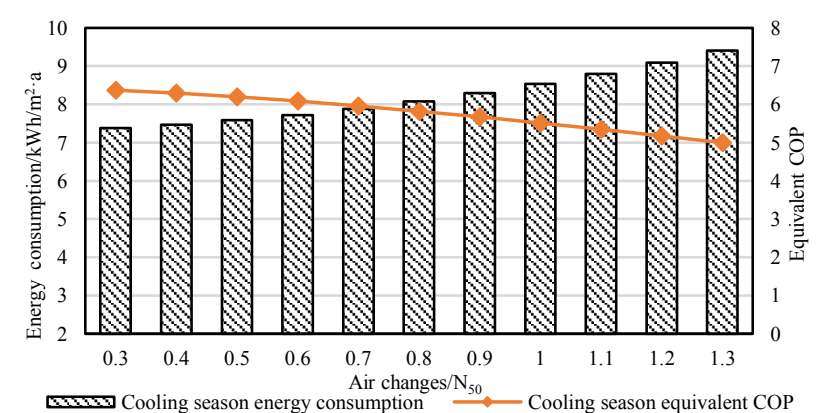

Fig.4. Energy consumption and equivalent COP of ventilation system under different air tightness in Guangzhou

Guangzhou is in the hot summer and warm climate zone, where the average monthly temperature in winter is higher than $10^{\circ} \mathrm{C}$ and does not require heating in winter. Figure 4 shows the energy consumption and equivalent COP of the ventilation system in the cooling season of Guangzhou. When the $\mathrm{N}_{50}$ is reduced from 1.3 to 0.3 , the energy consumption of the ventilation system reduced by $22 \%$, and the equivalent $\mathrm{COP}$ of the ventilation energy recovery system increased by 1.38 .

In all climate zones, when there is no natural ventilation, the improvement of air tightness can reduce the total energy consumption of cooling and heating of ventilation system to different degrees, which improves the equivalent $\mathrm{COP}$ of ventilation energy recovery system.

\subsection{Summer energy consumption of ventilation system under manual control (Mode 2)}

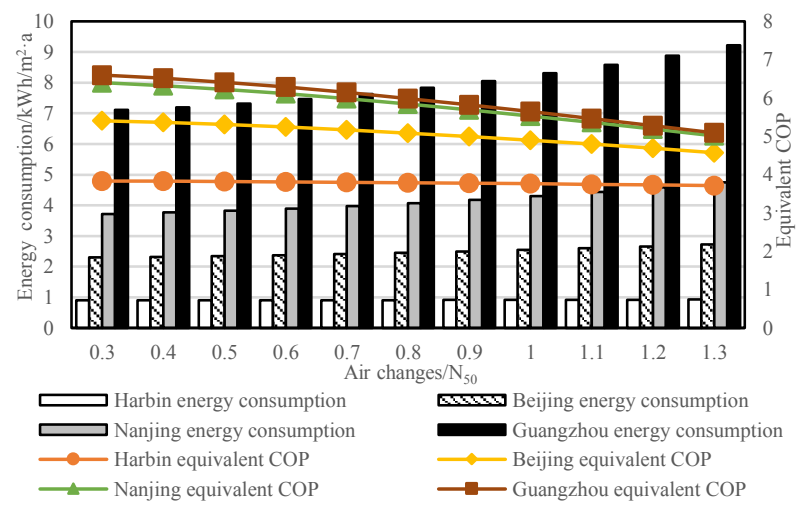

Fig.5. The relationship between energy consumption and air tightness of ventilation system under manual control in different climatic zones during cooling season

In real situation, people tend to open window when the outdoor environment is better than the indoor environment. Figure 5 shows the energy consumption and equivalent $\mathrm{COP}$ of the ventilation system in the cooling season of typical cities in different climate zones under the manual controlled mode. Compared with the closed window mode, the energy consumption is lower, and the efficiency is higher. When the $\mathrm{N}_{50}$ decreased from 1.3 to 0.3 , the energy consumption in Guangzhou and Nanjing decreased more, by $22 \%$ and $23 \%$ respectively, and the system equivalent COP increased by 1.4 and 1.5 . The energy consumption in Beijing and Harbin decreased by $15.4 \%$ and $3.2 \%$ respectively.

Taking $\mathrm{N}_{50}=0.6$ as an example, the energy consumption of Guangzhou, Nanjing, Beijing and Harbin decreased by $1.3 \%, 2.7 \%, 18.9 \%$ and $31.4 \%$ respectively in manual mode (Mode 2), compared to the mechanical ventilation only mode(Mode 1 ). The energy consumption of Beijing and Harbin decreased by a larger percentage.

\subsection{Energy consumption of ventilation with optimal automatic control (Mode 3)}

Figure 6 shows the energy consumption and equivalent efficiency of the ventilation system under the optimal automatic control mode (Mode 3 ) in the cooling season of different climate zones. Compared to the manual control mode, the energy consumption in Harbin can be reduced 
by $5 \%$ to $10 \%$, and the energy consumption in other zones is basically the same.

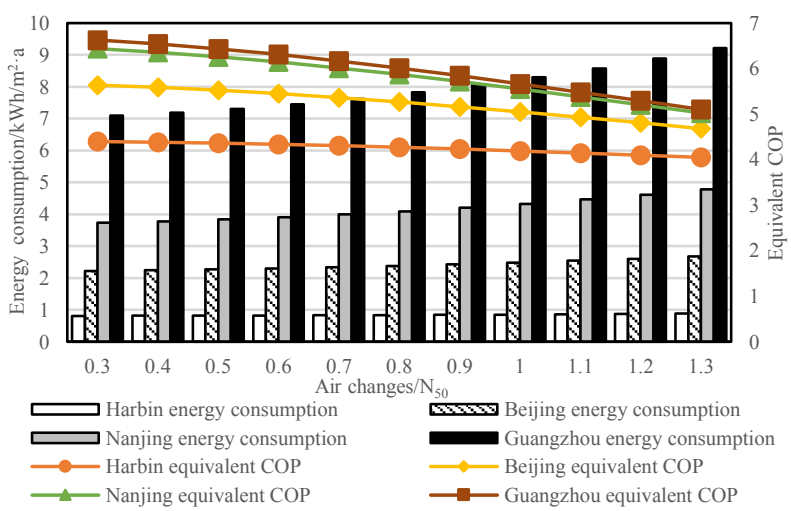

Fig.6. The relationship between energy consumption and air tightness of ventilation system under optimal automatic control in different climatic zones during cooling season

A switching enthalpy setpoint is used to switch between the use of natural ventilation and mechanical ventilation. It is discussed whether switching enthalpy setpoint will have an impact on the above result. Because the energy consumption for cooling in Harbin is trivial, the following are only discussed among Beijing, Nanjing and Guangzhou. Figure 7 shows the equivalent COP of energy recovery system in Beijing, Nanjing, and Guangzhou under different opening enthalpy during the cooling season.

Under the same air tightness and the same set opening enthalpy, the equivalent COP of Guangzhou is the highest, while that of Beijing is the lowest. When $\mathrm{N}_{50}$ is 0.6 and 1 , the energy consumption reaches the lowest value and the equivalent COP reaches the highest value when the opening enthalpy is about $59 \mathrm{~kJ} / \mathrm{kg}$. When the number of air changes $\mathrm{N}_{50}$ is 0.6 and 1 , the equivalent $\mathrm{COP}$ of Beijing system is increased by 0.28 and 0.2 respectively. The equivalent COP of Nanjing system is increased by 0.2 and 0.13 respectively, and the equivalent COP of Guangzhou system is increased by 0.08 and 0.06 respectively.

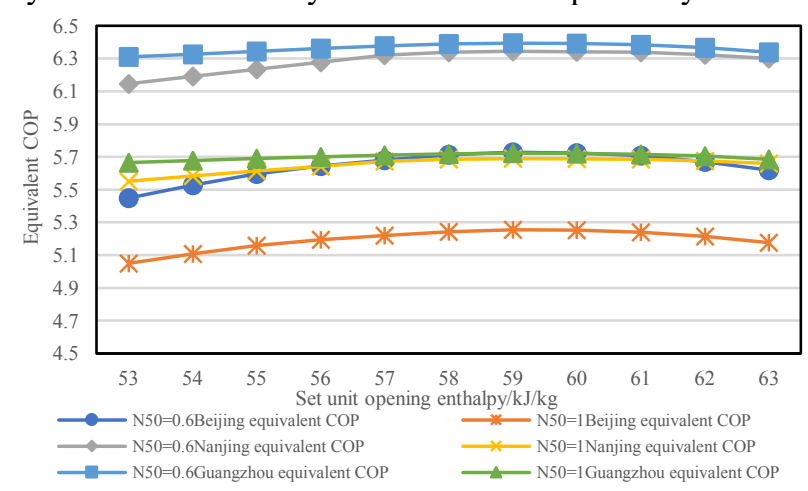

Fig.7. Equivalent COP of ventilation system under different setting enthalpy values in different climate zones

\subsection{Energy consumption of ventilation system under different energy recovery efficiency}

Sections 2.1-2.3 show the relationship between the air tightness, the energy consumption and the equivalent COP of ventilation system in different climatic zones.
This section further analyses the influence of different energy recovery efficiency on the above relationship.

Figure 8 and Figure 9 show the energy consumption and equivalent COP of the ventilation system in the heating season and cooling season in Beijing under different energy recovery efficiency. As the energy recovery efficiency increases, the energy consumption of the ventilation system in the heating season and the cooling season decreases, and the equivalent efficiency increases as the energy recovery efficiency increases. When the heat recovery efficiency is lower than $60 \%$, the equivalent $\mathrm{COP}$ is not sensitive to the airtightness. The equivalent COP increases rapidly as the energy recovery efficiency increases. When the heat recovery efficiency is higher than $60 \%$, and $\mathrm{N}_{50}$ is 0.6 , the equivalent COP of the system is obviously higher than that of $\mathrm{N}_{50}$ is 1 , and the difference increases as the energy recovery efficiency increases.

For every 0.1 increase in sensible heat recovery efficiency, the energy consumption of the ventilation system decreased by $8.8 \%$ and $7.6 \%$, respectively, when the N50 was 0.6 and 1 during the heating season. For every 0.1 increase in enthalpy recovery efficiency, the energy consumption of ventilation system decreased by $7.7 \%$ and $6.9 \%$, respectively, when the N50 of the cooling season was 0.6 and 1 .

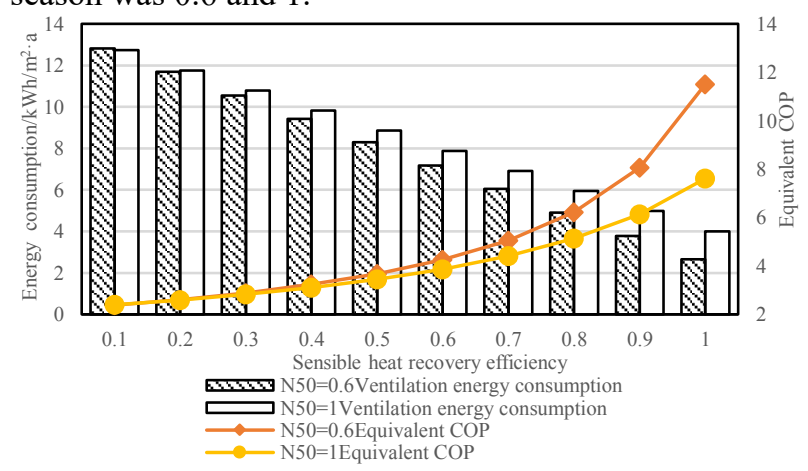

Fig.8. Energy consumption of ventilation system under different energy recovery efficiency in Beijing heating season

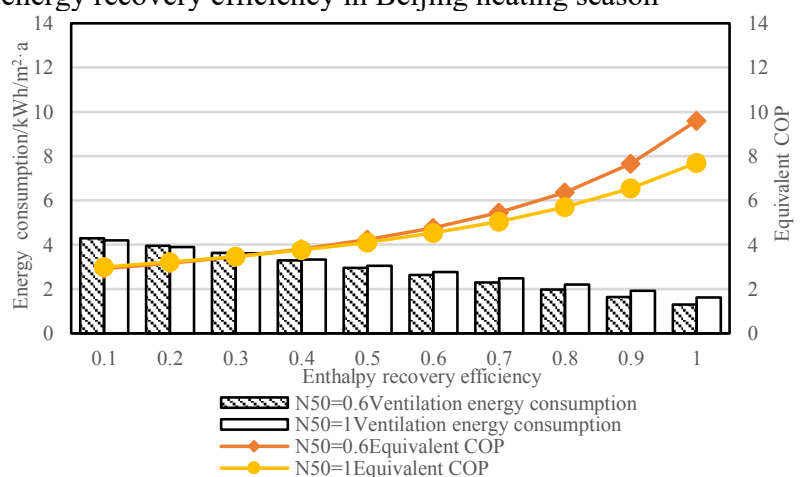

Fig.9. Energy consumption of ventilation system under different energy recovery efficiency in Beijing cooling season

Figure 8 and Figure 9 show the energy consumption and equivalent COP of the ventilation system in the heating season and cooling season in Beijing under different energy recovery efficiency. As the energy recovery efficiency increases, the energy consumption of the ventilation system in the heating season and the cooling season decreases, and the equivalent efficiency increases as the energy recovery efficiency increases. When the heat recovery efficiency is lower than $60 \%$, the 
equivalent $\mathrm{COP}$ is not sensitive to the airtightness. The equivalent $\mathrm{COP}$ increases rapidly as the energy recovery efficiency increases. When the heat recovery efficiency is higher than $60 \%$, and $\mathrm{N}_{50}$ is 0.6 , the equivalent COP of the system is obviously higher than that of $\mathrm{N}_{50}$ is 1 , and the difference increases as the energy recovery efficiency increases.

For every 0.1 increase in sensible heat recovery efficiency, the energy consumption of the ventilation system decreased by $8.8 \%$ and $7.6 \%$, respectively, when the $\mathrm{N}_{50}$ was 0.6 and 1 during the heating season. For every 0.1 increase in enthalpy recovery efficiency, the energy consumption of ventilation system decreased by $7.7 \%$ and $6.9 \%$, respectively, when the $\mathrm{N}_{50}$ of the cooling season was 0.6 and 1 .

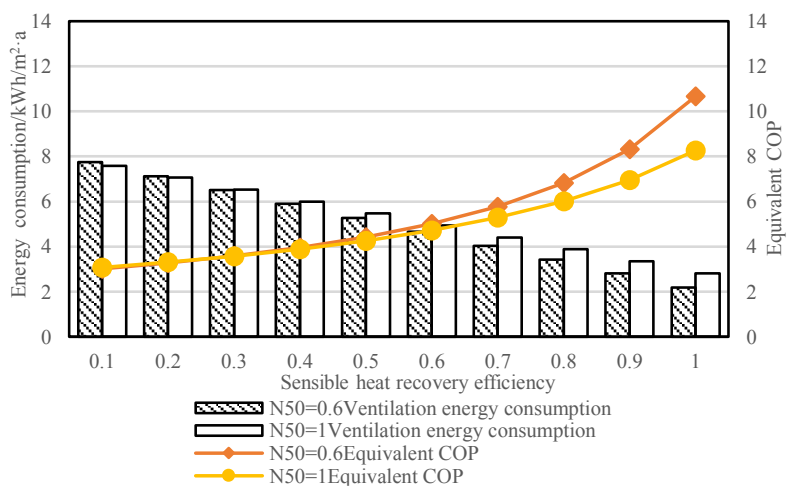

Fig.10. Energy consumption of ventilation system under different energy recovery efficiency in Nanjing heating season

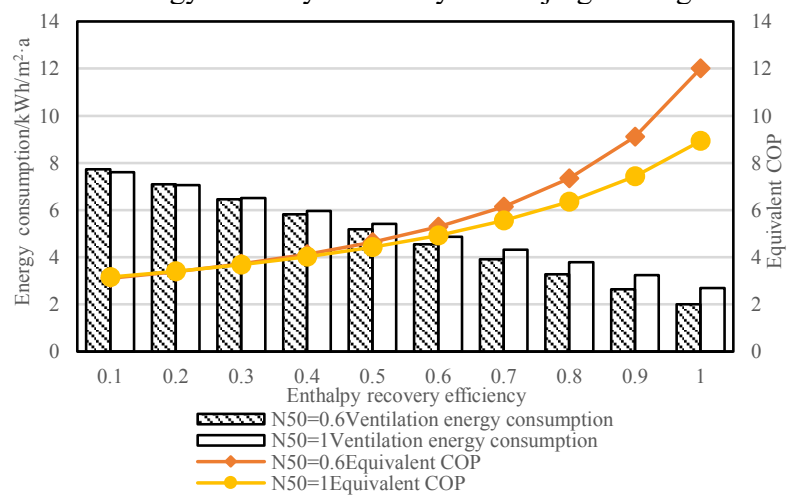

Fig.11. Energy consumption of ventilation system under different energy recovery efficiency in Nanjing cooling season

Figure 10 and Figure 11 show the energy consumption and equivalent COP of the ventilation system in the heating season and cooling season in Nanjing under different energy recovery efficiency. The trend of energy consumption and equivalent COP in Nanjing is consistent with that in Beijing. For every 0.1 increase in sensible heat recovery efficiency, the energy consumption of the ventilation system decreased by $8.0 \%$ and $7.0 \%$, respectively, when the $\mathrm{N}_{50}$ was 0.6 and 1 during the heating season. For every 0.1 increase in enthalpy recovery efficiency, the energy consumption of ventilation system decreased by $8.2 \%$ and $7.2 \%$, respectively, when the $\mathrm{N}_{50}$ of the cooling season was 0.6 and 1.

As the energy recovery efficiency increases, the energy consumption of the ventilation system decreases, and the equivalent COP of the ventilation energy recovery system increases. Especially under high energy recovery efficiency conditions, the improvement of air tightness can effectively improve the system equivalent COP.

\section{Conclusion}

1) When the only ventilation mode is mechanical ventilation, with the improvement of building air tightness, heating energy consumption in different climate zones decreases, and the equivalent efficiency of ventilation energy recovery system increases. In the cooling season, as the air exchanges rate $\mathrm{N}_{50}$ decreased, the energy consumption of the ventilation system in Harbin increased slightly. The cooling energy consumption in the other three typical cities is reduced, and the equivalent COP of the energy recovery system increased.

2) In the cooling season, considering the human behaviour by allowing manual operation of the window, the energy consumption of ventilation system is lower than that without natural ventilation, and the equivalent COP of ventilation energy recovery system is higher. With the improvement of air tightness, the energy consumption of ventilation system in Nanjing and Guangzhou decreases by $23 \%$ and $22 \%$ respectively.

3 ) In the cooling season, using optimal automatic control mode, the overall trend of energy consumption and equivalent COP of the ventilation system are similar to that of the manual control mode. An optimum value exists which can minimize the energy consumption and maximize the equivalent COP of ventilation system.

4) Under the same air tightness, the energy consumption of ventilation system decreases with the increase of energy recovery efficiency, and the equivalent COP of ventilation energy recovery system increases as the energy recovery efficiency increases. Under high energy recovery efficiency, the system equivalent COP with good air tightness is higher than that with poor air tightness, and the difference becomes larger as the energy recovery efficiency increases.

5) In most climate zones in China, the equivalent COP can reach 4.0 and 5.0 in heating season and cooling season respectively, which is competitive compared to typical air sourced air conditioning equipment.

\section{Acknowledgement}

This work is supported by National Key Research and Development Project of China No. 2017YFC0702600 (entitled :Technical System and Key Technology Development of Nearly zero enrgy building).

\section{References}

[1] China academy of building research. Technical guidelines for passive low energy buildings(Residential building), 2015.[S].

[2] ISO. Energy performance of buildings e calculation of energy use for space heating and cooling. ISO Standard 13790. Geneva: International Organization for Standardization; 2008. [S]. 
[3] Jokisalo J, Kurnitski J. Performance of EN ISO 13790 utilization factor heat demand calculation method in a cold climate. Energy and Buildings, 39(2) (2007):236-247.

[4] Persily A K. Understanding air infiltration in homes [M]. Center for Energy and Environmental Studies, Princeton University, 1982.

[5] Simonson C J, Besant R W. Heat and moisture transfer in energy wheels during sorption, condensation, and frosting conditions. Heat Transfer, 1998, 120: 699.

[6] Zhang X.D, Gong T.R, Guo Q, etc. Influence of building air tightness on energy consumption of dwelling house. Building Energy Efficiency, 04 (2016):61-64.

[7] Peng C, Yan D, Zhou X. Effect of building air tightness on energy consumption for heating. $H V \& A C, 09$ (2010):107-111.

[8] Feng X.H, Yan D, Peng C, etc. Influence of residential building air tightness on energy consumption. $H V \& A C, \mathbf{0 2}$ (2014):5-14.
[9] Lv Y.J, Xu W, Sun D.Y, etc. Research on calculation method of thermal load of fresh air for passive residential building with ultra-low energy consumption. Building Science, 06 (2015):80-85.

[10] Xu W, Lu Y.J, Sun D.Y. Calculation of fresh air system heating load under different strategies in ultra low-energy building. Building Science, 04 (2016):10-14.

[11] GB 50736-2012, Design code for heating, ventilation and air conditioning in civil buildings [S] 2012

[12] Lu Y.Q. Design manual of practical heating and air conditioning[M].Beijing: China Architecture \& Building Press, (2008).

[13] Zhu F.T, Zhu Q.F, Jiang Y. Building environment design simulation software $\operatorname{DeST}(5)$ : generation of the values of the extraneous factors influencing building thermal processes. $H V \& A C, 11$ (2004):5265. 